\title{
PROGRESS REPORT OF FY 1998 ACTIVITIES: CONTINUED DEVELOPMENT OF AN INTEGRATED SOUNDING SYSTEM IN SUPPORT OF THE DOE/ARM EXPERIMENTAL PROGRAM
}

Principal Investigators:

$\begin{array}{lr}\text { Edgeworth R. Westwater CIRES/NOAA } \\ \text { Yong Han } & \text { CIRES/NOAA } \\ \text { Vladimir Leuskiy } & \text { CIRES/NOAA }\end{array}$

ABSTRACT

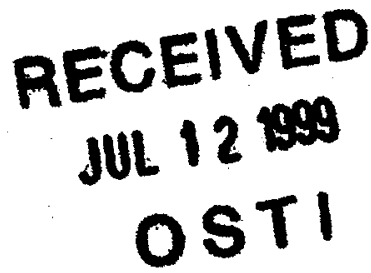

Both during September 15-30 1996 and September 15 - October 5, 1997, the Environmental Technology Laboratory (ETL) participated in an experiment at the Southern Great Plains (SGP) Cloud and Radiation Testbed (CART) site that was designed to study many of the ways that ARM is measuring water vapor. These experiments, called the Water Vapor Intensive Operating Periods (WVIOP), produced some results of significant importance to ARM water vapor measurements. We have spent the major portion of this years activities in analyzing results of these experiments, and improving algorithms for improving the measurement of precipitable water vapor (PWV) from instruments available at ARM. The most important ARM instrument for this measurement continues to be the Microwave Radiometer (MWR).

Measurements of water vapor at the North Slope of Alaska and Adjacent Arctic Ocean (NSA/AAO) CART site in Barrow, Alaska, are a potential problem because of the difficulty of radiosondes to measure low amounts of vapor during cold and extremely dry conditions. The applicability of MWR scaling to radiosondes is questionable because of the low sensitivity of these instrument during dry conditions. It has been suggested by the ARM Instaneous Radiative Flux Working Group and others that measurements of brightness temperature around $183 \mathrm{GHz}$ could be used to scale during the coldest and driest periods. However, the millimeter wavelengths are vulnerable to cloud effects from both liquid and ice. We have participated in the planning and will participate in the Millimeter wave Arctic Experiment that will evaluate microwave and millimeter wave radiometers during extremely cold conditions.

ETL has tested, both in an experiment at the Boulder Atmospheric Observatory and during the two Water Vapor Intensive Operating Periods in 1996 and 1997, a 5-mm scanning radiometer that measures low-altitude temperature profiles; both profiles of lapse rate and absolute temperature can be measured with the instrument. The technique and algorithms were developed for continental conditions and produced excellent agreement with in situ data. Due to ETL recommendations, an instrument of this type was purchased and will be deployed in the NSA. During this year, we have developed algorithms for this instrument in the NSA and to 


\section{DISCLAIMER}

This report was prepared as an account of work sponsored by an agency of the United States Government. Neither the United States Government nor any agency thereof, nor any of their employees, make any warranty, express or implied, or assumes any legal liability or responsibility for the accuracy, completeness, or usefulness of any information, apparatus, product, or process disclosed, or represents that its use would not infringe privately owned rights. Reference herein to any specific commercial product, process, or service by trade name, trademark, manufacturer, or otherwise does not necessarily constitute or imply its endorsement, recommendation, or favoring by the United States Government or any agency thereof. The views and opinions of authors expressed herein do not necessarily state or reflect those of the United States Government or any agency thereof. 


\section{DISCLAIMER}

Portions of this document may be illegible in electronic image products. Images are produced from the best available original document. 
blend the data with other sources of temperature information, such as Radio Acoustic Sounding Systems (RASS). In addition, we conducted an extensive analysis of the data from this instrument, and compared the data with a variety of ir situ ground truth.

\section{ALGORITHM DEVELOPMENT FOR MWR's AND PWV}

Results of the 1997 WVIOP (Westwater et al., 1998A; Westwater et al., 1998 B) indicated that the ARM MWR produced measurements of PWV that were about two millimeters higher than measurements from a variety of other independent instruments, such as two ETL MWR's, two Global Positioning Systems, and ARM Balloon Borne Sounding Systems. These results were in contrast to results obtained during WVIOP'96, in which ETL and ARM MWR's were basically in agreement. Since, both ARM and ETL share the same algorithms for deriving PWV from measured brightness temperatures, the disagreements could not have been related to algorithm differences. The most probable cause of the difference is radiometric calibration and we have consequently studied the assumptions that go into calibration procedures: horizontal stratification, beam width effects, pointing errors, and medium temperature determination. In addition, we have performed an exhaustive analysis of ARM MWR calibration data; i. e. "tip cal" data. Furthermore, we have developed a new "tip cal" equation, as well as a better method for determining antenna beamwidth corrections. Both of these methods will be available for ARM and will be submitted for open literature consideration.

\section{References}

E. R. Westwater, Y. Han, S. I. Gutman, and D. E. Wolfe: (1998 A): "Remote sensing of total precipitable water vapor by microwave radiometers and GPS during the 1997 Water Vapor Intensive Operating Period," Proc. IGARSS'9, 6-19 July, 1998, Seattle, WA (in press).

E. R. Westwater, Y. Han, S. I. Gutman, and D. E. Wolfe: (1998 B): "Remote sensing of column integrated water vapor by microwave radiometers and GPS during the 1997 Water Vapor Intensive Operating Period," Proc. Eighth ARM Science Team Meeting, March 23-27th, 1998, Tucson, Arizona, (in press)

\section{PARTICIPATION IN NSA/AAO WATER VAPOR EXPERIMENT}

There are concerns about the ability of the ARM Microwave radiometer (MWR) to derive accurate measurements of Precipitable Water Vapor (PWV) during the coldest and driest of conditions, because of the relatively weak response of the $22 \mathrm{GHz}$ emission to PWV amounts below about $5 \mathrm{~mm}$. A theoretical analysis (Jones and Racette, 1998) has indicated that measurements of atmospheric emission in the $\mathrm{mm}$ wavelength region can provide increased accuracy of PWV determination during these cold conditions. We are now participating in the planning and will participate in the Millimeter-wave Radiometric (MMWR)-Arctic experiments to determine if radiometric measurements around the much stronger $183 \mathrm{GHz}$ absorption line can yield improved measurements of PWV during the extreme cold conditions. We have joined a 
team with radiometric expertise that will conduct this experiment at the NSAVAAO during March of 1999. The team consists of Paul Racette of NASA/GSCF, Al Gasiewski of NOAA/ETL, and both Ed Westwater and Yong Han. Racette, Gasiewski, and Westwater visited the NSA/AAO CART site on June 5, 1998, did a site survey, and met with Dr. Bernie Zak, Dr. Knut Stamnes, and Kevin Widener, all of whom play key roles in the NSA/AAO CART site.

The objective of the proposed MMWR experiment is to investigate the retrieval accuracy of PWV using a variety of microwave and millimeter wave measurements obtained during the driest conditions experienced in the arctic region. The investigation will yield an assessment of the performance for retrieving very low amounts of water vapor using different combinations of frequencies. Radiometers spanning the frequency range from $20.6 \mathrm{GHz}$ to $325 \mathrm{GHz}$, and possibly $340 \mathrm{GHz}$, will be deployed in a variety of scanning modes. The assessment will provide basis for a qualified decision as to the most cost effective strategy for measuring PWV under all conditions. A secondary objective is to assess the response of the millimeter wave channels to the presence of ice clouds. Cloud radar and lidar measurements already being taken at the NSA/AAO site will be of substantial benefit in furthering this objective. The extent to which the scattering will affect the retrieval of PWV and whether information about ice cloud distributions may be extracted from millimeter and submillimeter wave measurements will also be investigated.

We plan to deploy the following NASA and ETL instruments totaling 31 radiometric channels:

MIR (NASA): $89,150,183.31 \pm 1,183.31 \pm 3,183.31 \pm 7,220,(325.15 \pm 1,325.15 \pm 3$, and $325.15 \pm 8 \mathrm{GHz})^{*}$

DoER (NASA): $20.735,21.485,22.235,22.985,23.735,36.5$, and $89.0 \mathrm{GHz}$

MWR (ETL): 20.6 and $31.65 \mathrm{GHz}$

Scanning- $\mathrm{O}_{2}$ (ETL): $60.5 \mathrm{GHz}$

Scanning- $\mathrm{CO}_{2}$ band IR (ETL): $14 \mu \mathrm{m}$

PSR/S (ETL)*: $18.7,21.5,89,183 \pm 1,183 \pm 3,183 \pm 7,183 \pm 15,325 \pm 1,325 \pm 3,325 \pm 8$, $340 \mathrm{GHz}$.

* The PSR/S will be deployed pending completion of a new sub millimeter-wave scanhead incorporating the $325 \mathrm{GHz}$ spectrometer. If it cannot be completed in time for the experiment, the $325 \mathrm{GHz}$ spectrometer will be installed in the MIR.

Reference

Jones, D. C., and P. E. Racette, 1998: Ground-based retrieval of very low to high columnar integrated water vapor using combined millimeter- and microwave observations. Proc. 
International Geophysics And Remote Sensing Symposium '98, 6-10 July, 1998, Seattle, Washington (in press)

\section{TESTING OF 5-MM SCANNING RADIOMETERS}

We tested two techniques for deriving low-altitude temperature profiles at an experiment conducted from November 1996 to January 1997 at the Boulder Atmospheric Observatory (BAO). Both of these techniques will be deployed at the ARM field site on the NSA. The first technique uses a scanning, single wavelength, $5-\mathrm{mm}(60 \mathrm{GHz})$ microwave radiometer to measure vertical temperature profiles. The second technique is a Radio Acoustic Sounding System (RASS) that operated at $915 \mathrm{MHz}$. Ground truth for the experiment was available from in situ measurements at the BAO. The BAO has an instrumented 300-m tower with 5-min measurements of temperature and relative humidity available at the surface and at altitudes of 10 , $50,100,200$, and $300 \mathrm{~m}$. The differences between the radiometers and the tower sensors were about $1^{\circ} \mathrm{C}$ rms. The accuracy using an in situ temperature measurement at the radiometer height as a predictor was also evaluated; at the 200 and 300 -m levels, only about $4{ }^{\circ} \mathrm{C} \mathrm{rms}$ accuracies resulted. During the experiment, the RASS occasionally experienced radio frequency interference; to eliminate these effects, a quality control algorithm for the RASS system was developed and evaluated. Table 1 shows results from the BAO experiment.

In addition, experiment were held in September 15-30 1996 and September 15-October 5 1997 at the Department of Energy's Atmospheric Radiation Program Southern Great Plains site in north central Oklahoma. For these experiments, we compared data from ETL's scanning 5$\mathrm{mm}$ radiometer with 3-hourly radiosonde from the ARM Balloon Borne Sounding System (BBSS) and with the ARM 60-m tower. Quality control on the radiosondes was provided by comparisons with independent in situ surface and 60 -m tower observations. The agreement between the radiometric profiles and the quality-controlled radiosondes was better than $1{ }^{\circ} \mathrm{C}$ up to $800 \mathrm{~m}$. In addition to the in situ comparisons, theoretical analyses of the scanning radiometer systems have been conducted. The effects of angular resolution, noise level, prediction from in situ measurements, and vertical resolution have been examined. These results are all consistent with experimental observations, but suggest ways in which current systems may be improved. Figure 1 (A) shows experimental predictions of temperature retiveval accuracy and Figure 1 (B) shows experimentally achieved results.

The prospects for combining RASS and radiometric retrievals from the scanning radiometer at the NSA/AAO are intriguing. The ability of the radiometer to measure temperature from the surface to 300 or $400 \mathrm{~m}$, the region of overlap between radiometer and RASS, and the potential of RASS to probe much higher than the radiometer, all suggest that such a combination would be fruitful. In Figure 2, we show temperature profiles from the radiometer, RASS, and the tower. There is a region of overlap where the retrievals agree well with other, as well as non-intersecting regions, where each system could independently contribute information. A variety of retrieval algorithms could be used to combine such data if the accuracies of the data; i.e., their error covariance matrices, are known. 


\section{FY 1999 PLANS}

\section{- ALGORITHM DEVELOPMENT FOR MWR's AND PWV}

We plan to complete the analysis of ETL and ARM data that were obtained during WVIOP'96 and WVIOP'97 and submit the results to the open literature. After closure on the ARM MWR calibration problems, we will provide to the ARM MWR instrument mentor our new "tip cal" software for possible implementation. After internal consistency is obtained between ARM data from the MWR, BBSS, Raman lidar, and possibly the GPS, we will return to the blending of these data uning Kalman Filtering. After testing, we will deliver to ARM a computer algorithm, with appropriate documentation, for assimilation of the remote sensing data by KF. In addition, radiosonde information will be available at least twice-a-day, and during IOPs, perhaps every 3 hours. A modest extension of the KF technique would also incorporate radiosonde profiles into the retrievals, and we propose to develop this portion of the algorithm as well.

\section{- PARTICIPATION IN NSA/AAO WATER VAPOR EXPERIMENT}

Our experiment plan entails the acquisition and subsequent analysis of a data set comprised of microwave and millimeter-wave radiometric measurements acquired over 21 days during the 1999 arctic winter in March of 1999. The driest, and hence coldest conditions are the most desirable to meet the experiments objectives. Prevailing clear sky conditions are the most desirable. ETL's responsibilities for the experiment include operation of several radiometers and contributing to the analysis of the $183 \mathrm{GHz}$ data taken by MIR.

\section{- TESTING OF 5-MM SCANNING RADIOMETERS}

We plan to evaluate the installation, operation, and performance of the ATTEX scanning 5 -mm radiometer that has been purchased by ARM and will be installed at the NSA/AAO in August-September 1998. We plan to travel to Barrow to help coordinate (both with Russian and ARM personnel) with this installation. After successful installation, we plan to evaluate the accuiacy of the instrument and to implement our algorithms for combining RASS and radiometer data. Other data products that we will evaluate will be the combination of ATTEX and MWR data during "tip cals" and a quality control method for RASS, using scanning radiometer data, that we developed.

\section{FY 2000 PLANS}

\section{Southern Great Plains CART}

We will change our focus from measurements of water vapor to those of clouds. The WVR has already been shown to measure liquid water path and, with the addition of ceilometer 
data, to yield a first-order profile of liquid water density (Han and Westwater, 1995). Although WVR data is widely used for the determination of liquid water path, only a very limited amount of in situ ground truth data has been used for verification. We propose to participate in cloud IOPs where in situ and other sources of cloud data will be available. The newest source of data will be that the CART cloud radar, which will add important information on cloud thickness. In addition, we plan to evaluate a technique using both GPS and MWR data to derive cloud liquid

\section{North Slope of Alaska}

We will complete the analysis of the radiometer data taken during the 1999 NSA/AAO millimeter wave arctic experiment and make recommendations to ARM about $183 \mathrm{GHz}$ deployment. An open literature article will also be submitted.

The generality of the Kalman Filtering method is such that any measured functional of the temperature or water vapor profile can be incorporated into the estimation algorithm. Thus, without any change in the basic mathematical formalism, data from satellite radiances can be directly utilized. We will to gather satellite data from the DMSP/SSM/I and the most recent NOAA polar orbiter data to blend with NSA remote sensor data. The use of measured radiances of course requires an appropriate forward model of the type that several science team members, especially S. A. Clough, have been developing.

\section{PAPERS PUBLISHED SINCE OCTOBER 1, 1997}

Han, Y. , E. R. Westwater, and R. A. Ferrare (1997): "Recent Results in Deriving Water Vapor Profiles from Combined Remote Sensor Observations using Kalman Filtering"

Proceedings of Sixth ARM Science Team Meeting, San Antonio, Texas, March 4-7, 1996.121 124.

Y. Han , E. R. Westwater, and R. A. Ferrare (1997): Applications of Kalman Filtering to Derive Water Vapor from Raman Lidar and Microwave Radiometers. J. Atmos. Oceanic Technol., vol. 14, No. 3, Part 1, June, 1997. pp. 481-487.

D. Turner, T. Shippert, J. Liljegren, Y. Han, and E. Westwater (1997) Initial analysis of water vapor and temperature profiles retrieved from integrated ground-based remote sensors. Proc. 6th ARM Science Team Meeting, San Antonio, TX, March 4-7, 1996 327-330.

E. R. Westwater, Y. Han, V. G. Irisov, V. Leuskiy, E. N. Kadygrov, and S. A. Viazankin (1997): "Remote Sensing of Boundary-Layer Temperature Profiles by a Scanning 5-mm Microwave Radiometer and RASS: A Comparison Experiment." Proc. IGARSS'97, 4-8 August 1997 , Singapore.2093-2096.

Westwater, E. R. , (1997): Remote sensing of tropospheric temperature and moisture by integrated observing systems. Bull. Amer. Meteor. Soc.,78, 1991-2006 
E. R. Westwater, Y. Han, V. Leuskiy, V. Irisov, E. Kadygrov, and S. A. Vaizankin (1998): Multi-Sensor Measurements of Boundary-Layer Temperature Profiles. Proceedings of Seventh ARM Science Team Meeting, March 3-7, 1997 , pp. 311-315.

E. R. Westwater, Y. Han, V. G. Irisov, V. Ye Leuskiy, Yu. G. Trokhimovskiy, and C. W. Fairall (1998): Evaluation of a Scanning 5-mm Radiometer for Obtaining Air-Sea Temperature Difference and Low-Level Atmospheric Stability. Proceedings of Seventh ARM Science Team Meeting, March 3-7, 1997, pp. 245-249.

Y. G. Trokhimovski, E. R. Westwater, Y. Han, and V. Ye. Leuskiy (1998):"The results of Air and sea surface temperature measurements using a $60 \mathrm{GHz}$ microwave rotating radiometer," IEEE TGARS, Vol. 36, No. 1, 3-15.

Solheim, F., J. R. Goodman, R. H. Ware, E. R. Westwater, and Y. Han: (1998) "Radiometric temperature, water vapor, and cloud liquid water profiling with various inversion methods," Radio Sci., 33, 393-404.

E. R. Westwater, Y. Han, V. G. Irisov, V. Ye. Leuskiy, Yu. G. Trokhimovski, C. W. Fairall, and A. Jessup (1998): Sea-Air and Boundary Layer Temperatures Measured by a Scanning 5-mm wavelength (60 GHz) Radiometer: Recent Results. Radio Sci., 33, 291-302.

E. R. Westwater, Y. Han, S. I. Gutman, and D. E. Wolfe: (1998): "Remote sensing of total precipitable water vapor by microwave radiometers and GPS during the 1997 Water Vapor Intensive Operating Period," Proc. IGARSS'9, 6-19 July, 1998, Seattle, WA (in press).

Kadygrov, E. N., Gaikovich, K. P., Westwater, E. R., Han, Y., and Widener, K. (1998): "Potential performance of boundary layer temperature profile microwave remote sensing: Results of filed testing at various latitude zones." Proc. Eighth ARM Science Team Meeting, March 2327th, 1998, Tucson, Arizona, (in press)

Han, Y., Ed R. Westwater, J. Shaw, and J. H. Churnside, (1998): "Comparison of boundarylayer temperature retrievals from a FTIR and a 5-mm microwave radiometer during the 1997 Water Vapor Intensive Operating Period," Proc. Eighth ARM Science Team Meeting, March 23-27th, 1998, Tucson, Arizona, (in press)

E. R. Westwater, Y. Han, S. I. Gutman, and D. E. Wolfe: (1998) "Remote sensing of column integrated water vapor by microwave radiometers and GPS during the 1997 Water Vapor Intensive Operating Period," Proc. Eighth ARM Science Team Meeting, March 23-27th, 1998, Tucson, Arizona, (in press)

E. R. Westwater, Y. Han, K. Gaikovich, E. N. Kadygrov, and A. S. Viazankin, (1998): "Remote sensing of boundary layer temperature profiles by scanning microwave radiometers and RASS: results of an intercomparison experiment," Proc. $4^{\text {th }}$ Int. Sym. on Tropospheric Profiling, Snowmass, Colorado, (in press). 
Fig. 1. (A) Theoretical accuracy of 5-mm scanning radiometer as a function of height for various choices of radiometer error and for prediction based on surface observations. (B) Rms differences as a function of height above the surface between profiles of temperature as measured by the ETL scanning radiometer, as estimated by surface temperature, and measured by radiosondes at the ARM SGP CART site 
Figure 2. Profiles of temperature as measured by the ATTEX radiometer, RASS, and BAO in situ sensors. January $7,1997,2100$ UTC. 


\begin{tabular}{|c|c|c|c|c|c|}
\hline $\begin{array}{l}\text { Tower } \\
\text { level }(\mathrm{m})\end{array}$ & Sample sde & $\begin{array}{l}\mathrm{T}(10 \mathrm{~m}) \\
\text { rms bias } \mathrm{n}\end{array}$ & $\begin{array}{c}\text { ETL } \\
\text { rms bias } n\end{array}$ & $\begin{array}{l}\text { ATTEX } \\
\text { rms bias } \mathrm{n}\end{array}$ & $\begin{array}{c}\text { RASS } \\
\text { rms bias } \mathrm{n}\end{array}$ \\
\hline 10 & 10.7 & $-\quad--$ & $-\quad-$ & $\begin{array}{lll}0.9 & 0.3 & 2103\end{array}$ & --- \\
\hline 50 & 11.2 & $1.7-0.22103$ & $\begin{array}{llll}1.0 & 0.0 & 2351\end{array}$ & $0.9-0.32103$ & - \\
\hline 100 & 11.4 & 2.30 .32103 & $1.2-0.62351$ & $0.9-0.12103$ & - \\
\hline 200 & 11.5 & $3.6-1.12103$ & $1.0-0.42351$ & $0.8-0.12103$ & $\begin{array}{ll}0.9 & 0.4\end{array}$ \\
\hline 300 & 11.2 & 3.81 .11243 & $1.2 \quad 0.01403$ & $\begin{array}{llll}0.9 & 0.2 & 1243 \\
\end{array}$ & 1.31 .0 \\
\hline
\end{tabular}

